\section{Novel growth factors involved in the pathogenesis of proliferative vitreoretinopathy}

DR Hinton ${ }^{1,2,3}, \mathrm{~S} \mathrm{He}^{2}, \mathrm{ML} \mathrm{Jin}^{2}, \mathrm{E}$ Barron ${ }^{3}$ and SJ Ryan ${ }^{1,3}$
${ }^{1}$ Department of

Ophthalmology

Keck School of Medicine

of the University of

Southern California

Los Angeles, CA, USA

${ }^{2}$ Department of Pathology Keck School of Medicine

of the University of

Southern California

Los Angeles, CA, USA

${ }^{3}$ Doheny Eye Institute Los Angeles, CA, USA

Correspondence:

SJ Ryan MD

Department of

Ophthalmology

Keck School of Medicine at

USC

1450 San Pablo St

DEI 5600

Los Angeles

CA 90033, USA

Tel: 3234426444

E-mail: sryan@usc.edu
Abstract

Aims To determine whether hepatocyte growth factor (HGF) and connective tissue growth factor (CTGF) are expressed in human specimens of proliferative vitreoretinopathy (PVR) and to propose a model of PVR pathogenesis based upon the known activities of these growth factors. Methods Immunohistochemical methods (ABC Elite) were used to demonstrate the presence of HGF and CTGF in cryostat sections of five human PVR membranes. Results In each of the five PVR membranes, stromal cells were immunohistochemically positive for both HGF and CTGF. Based upon this information and the known actions of these growth factors, a model of PVR pathogenesis was developed. In this model, injury of the retina induces an inflammatory response that upregulates HGF expression inducing the formation of multilayered groups of migratory retinal pigment epithelial cells (RPE). These RPE, present in a provisional extracellular matrix, come in contact with vitreous containing TGF- $\beta$. The TGF- $\beta$ is activated, upregulating expression of CTGF. Under the influence of TGF- $\beta$ and CTGF, RPE become myofibroblastic and fibrosis ensues. Retinal traction induces further detachment continuing the cycle of retinal injury. Conclusions HGF and CTGF are expressed in PVR membranes and may play important roles in the pathogenesis of PVR. The expression and function of these growth factors should be critically examined in human PVR specimens, in in vitro cultures of RPE, and in animal models of PVR.

Eye (2002) 16, 422-428. doi:10.1038/

sj.eye. 6700190
Keywords: proliferative vitreoretinopathy; hepatocyte growth factor; connective tissue growth factor; immunohistochemistry

\section{Introduction}

Proliferative vitreoretinopathy (PVR) is the most common cause of failed repair of a primary rhegmatogenous retinal detachment (RRD). ${ }^{1,2}$ It occurs when traction-generating cellular membranes develop in the vitreous and inner or outer surfaces of the retina after RRD or major ocular trauma. ${ }^{1,3}$ A critical cell type involved in this epiretinal membrane formation is the RPE cell. ${ }^{4,5}$ These cells proliferate and migrate from the RPE monolayer to form sheets of dedifferentiated cells within a provisional extracellular matrix (ECM) that contains fibronectin and thrombospondin..$^{5-7}$ The cellular membrane becomes progressively paucicellular and fibrotic over time. ${ }^{7}$ Normal ocular wound healing involves a tightly coordinated series of events including recruitment and activation of inflammatory cells, release of cytokines, activation and proliferation of ocular cells, secretion of extracellular matrix, tissue remodeling and repair. ${ }^{8}$ The mechanisms of protracted wound healing, as is found in PVR, are unknown but are presumed to include either sustained or dysregulated growth factor responses. ${ }^{4}$

In the normal eye, the RPE forms a monolayer of immobile, polarized, nonproliferating cells joined by apical tight and adherent junctions. ${ }^{9}$ Within 24 hours of retinal detachment in the cat, RPE cells begin to proliferate and form multi-layered groups of dedifferentiated cells. ${ }^{10}$ The signal for this dramatic change in the RPE monolayer may be related to loss of contact or signaling from 
photoreceptors. ${ }^{4,10}$ Alternatively, it may be a response to signals, such as tumor necrosis factor-alpha (TNF), secreted by inflammatory cells drawn to the lesion. ${ }^{11}$ Previous work has established the important adjunctive role of TNF as a mediator of RPE activation and platelet-derived growth factor (PDGF) as an important mitogen, chemoattractant, and mediator of cellular contraction. ${ }^{4,5,12-17}$ The cytokine TGF- $\beta$ is a pivotal contributor to tissue fibrosis, and the TGF- $\beta 2$ isoform is predominant in an inactive form in normal vitreous. ${ }^{18,19}$ Thrombospondin-1 represents a likely activator of TGF- $\beta$ within tissue. ${ }^{20,21}$ TGF- $\beta$ levels are elevated in PVR vitreous and they correlate with the presence of intraocular fibrosis, however little is known about the downstream mediators of this effect. ${ }^{20}$ In this paper, we propose that novel growth factors (hepatocyte growth factor and connective tissue growth factor) mediate two critical, and in many ways opposing, activities in PVR; the development of multilayered groups of dedifferentiated RPE from an intact monolayer early in the process, and their subsequent transformation into a fibrotic paucicellular membrane later in the process.

\section{Methods}

PVR membranes were surgically excised during vitrectomy surgery in five patients. The tenets of the Declaration of Helsinki, Finland, were followedinformed consent was obtained, and institutional human experimentation committee approval was granted for this study. The basic characteristics of the excised membranes are described in Table 1.

Each of the fresh membranes was placed in isotonic saline at $4^{\circ} \mathrm{C}$, then snap-frozen in optimum cutting temperature compound (Ames/Miles, Elkhart, IN, USA) within $1 \mathrm{~h}$. Each specimen was sectioned on a cryostat into $6 \mu \mathrm{m}$ frozen sections on glass slides for immunohistochemical analysis. The sections were fixed in reagent grade acetone for $5 \mathrm{~min}$ at room temperature and stored at $-80^{\circ} \mathrm{C}$. Thawed tissue sections were air-dried, rehydrated with phosphate-

Table 1 Immunohistochemical staining of PVR membranes for HGF and CTGF

\begin{tabular}{lcc}
\hline Case number & HGF & CTGF \\
\hline 1 & ++ & ++ \\
2 & + & +++ \\
3 & + & +++ \\
4 & + & ++ \\
5 & +++ & +++ \\
\hline
\end{tabular}

$1+$, weak, focal staining ( $<10 \%$ of cells).

$2++$, moderate to strong staining, (up to $50 \%$ of cells).

$3+++$, intense staining ( $>50 \%$ of cells). buffered saline (PBS; $\mathrm{pH} 7.4$ ), and incubated with blocking serum for $15 \mathrm{~min}$. Sections were incubated for 60 min with the polyclonal primary antibody of interest then washed for 15 min with PBS.

Immunoperoxidase detection was performed using the ABC Elite kit (Vector, Burlingame, CA, USA) with aminoethylcarbizole as the red chromogen. Slides were then rinsed with tap water, counterstained with hematoxylin, and mounted with glycerin-gelatin medium. Polyclonal antibodies against HGF (Santa Cruz Biotechnology, Santa Cruz, CA, USA) were used at a dilution of 1:200, while antibodies against CTGF (Fibrogen, South San Francisco, CA, USA) were used at a dilution of 1:400.

\section{Results}

All five membranes showed expression for both HGF and CTGF (Table 1). HGF expression was generally higher in cellular regions of the membrane than in fibrotic regions (Figure $1 \mathrm{a}, \mathrm{b}$ ). HGF immunoreactivity was predominantly associated with the cytoplasm of the stromal cells. CTGF expression was prominent in both cellular and fibrotic regions of the membranes (Figure 1c, d). CTGF staining was present both in association with the stromal cells and the extracellular space.

\section{Discussion}

\section{Hepatocyte growth factor (HGF)}

We hypothesize that HGF is a major mediator of early PVR, inducing the separation of RPE from the monolayer and (along with TNF and PDGF) the formation of an invasive, cellular, non-fibrotic membrane containing dedifferentiated RPE. HGF, also known as scatter factor, is a pleiotropic growth factor with marked cross species activity that was originally derived from platelets. ${ }^{22,23}$ HGF is a heparin-binding glycoprotein that is secreted as a single-chain (preHGF) precursor that in situations such as tissue damage is proteolytically cleaved to form a functional heterodimer joined by a single disulfide bond. HGF acts predominantly on epithelial cells where it has mitogenic, morphogenic and motogenic activities. ${ }^{24-26}$ These effects are mediated through a transmembrane tyrosine kinase surface receptor known as c-Met or HGFR. ${ }^{24}$

We previously reported that RPE secrete HGF and express a functional HGFR making the HGF/HGFR system a potential autocrine loop for RPE. ${ }^{27}$ As shown in this paper and in work by others, increased expression of HGF/HGFR is present in human PVR 

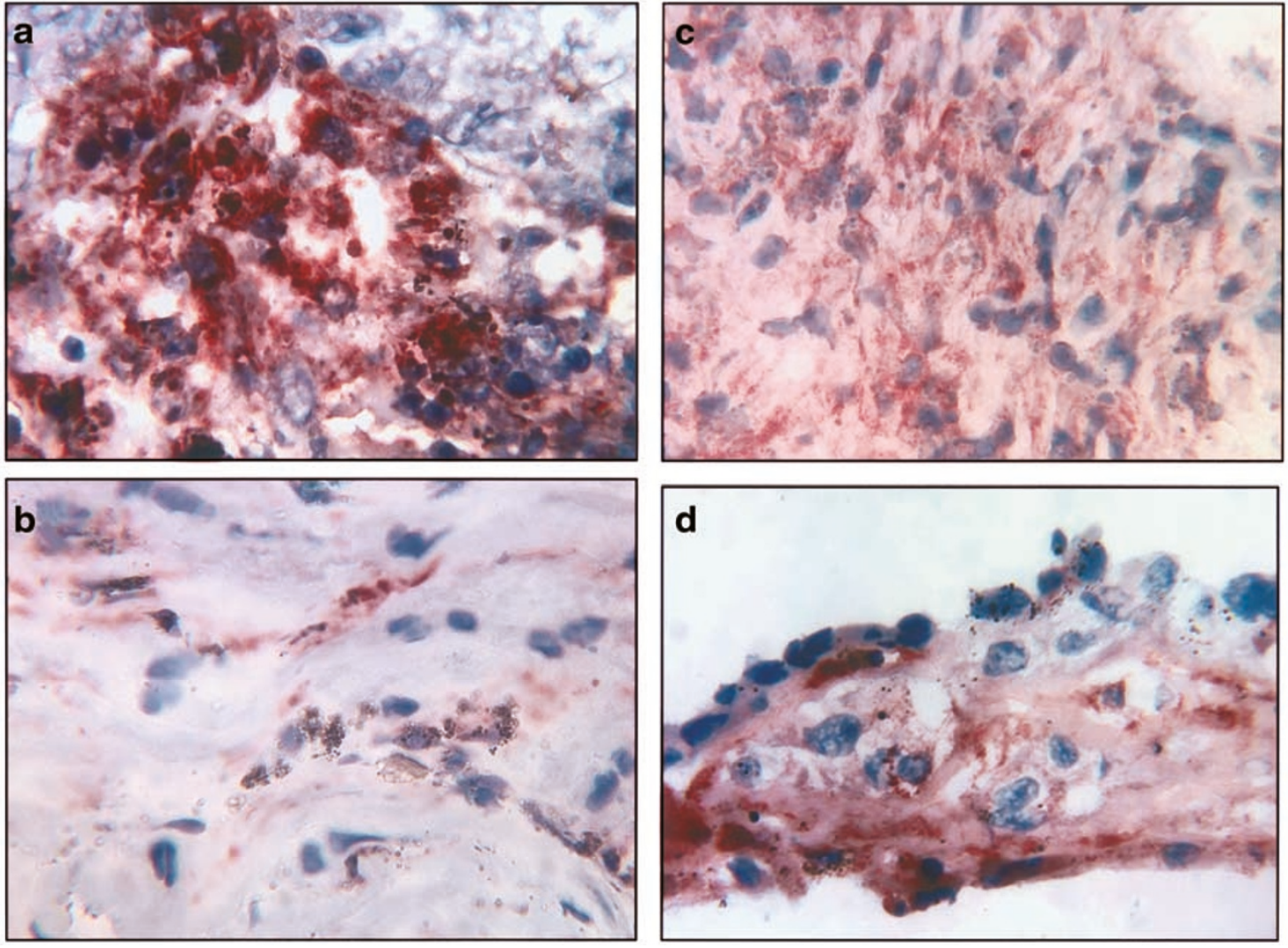

Figure 1 HGF and CTGF are expressed in surgically excised human PVR membranes. The cryostat tissue sections were stained immunohistochemically using polyclonal antibodies against HGF and CTGF. Detection was achieved with the ABC Elite kit using aminoethylcarbizole as the red chromogen. A weak hematoxylin counterstain is present. HGF is prominent within the stromal cells of cellular membranes (a) and to a lesser extent in stromal cells of fibrotic membranes (b). CTGF is found both associated with cells and in the extracellular space in cellular membranes (c) and fibrotic membranes (d). Magnification $\times 400$.

membranes and HGF is increased in the vitreous of PVR patients. ${ }^{28-30}$ Interestingly, HGF scatter activity is higher in patients with RRD than PVR while total HGF increases with severity of disease suggesting that this growth factor may have a critical role early in the course of the disease. ${ }^{29,30}$ Consistent with this finding, our results show that HGF expression was more prominent in cellular regions of membranes than those that were predominantly fibrotic. HGF interacts with a variety of extracellular matrix molecules and has high affinity interactions with thrombospondin- $1 .{ }^{31}$ In cultured epithelial cells of varied phenotype, HGF has been shown to modulate the localization and function of intercellular junctional proteins. ${ }^{32-35}$ HGF has also been shown to be anti-apoptotic ${ }^{36}$ and anti-fibrotic. ${ }^{37-40}$ Pro-inflammatory cytokines such as TNF and interferon-gamma upregulate expression of $\mathrm{HGF}_{,}{ }^{41}$ while HGF itself upregulates expression of TGF- $\beta .^{42}$ We have shown that HGF induces major phenotypic changes in RPE. ${ }^{43}$ This is seen within an intact monolayer in explants and in vivo. ${ }^{44}$ It results in phosphorylation and then loss of intercellular junctions, and facilitation of migration from the monolayer. ${ }^{43}$ We predict that these morphologic changes will promote retinal detachment in vivo and will be associated with widespread alterations in patterns of RPE gene expression.

\section{Connective tissue growth factor (CTGF)}

We hypothesize that CTGF, in the presence of TGF- $\beta$, is the major mediator of retinal fibrosis. CTGF is a secreted cysteine-rich heparin-binding polypeptide growth factor. ${ }^{45,46}$ It is a member of the $\mathrm{CCN}$ family of genes (ctgf/cyr61/nov) that includes six members encoding proteins that participate in fundamental biologic processes including wound healing and fibrosis. ${ }^{46}$ Like other CCN members, CTGF contains four functional domains including an IGF binding protein, von Willebrand factor, thrombospondin-1, and cystine knot domains. ${ }^{46}$ CTGF is rapidly upregulated after serum or TGF- $\beta$ stimulation; however it is unstable in vitro with a $\mathrm{t}_{1 / 2}$ of $60-90 \mathrm{~min} .{ }^{47}$ Little is known about the mechanism of CTGF degradation; 
however, various CTGF fragments have been shown to accumulate in tissue culture or body fluids and they may retain biologic activity. ${ }^{46,48-50}$ CTGF functions as a downstream mediator of TGF- $\beta$ action on fibroblasts where it stimulates cell proliferation and cell matrix deposition (collagen 1 and fibronectin). ${ }^{45-46,51} \mathrm{In}$ contrast to HGF, CTGF induces apoptosis. ${ }^{52,53}$ The receptor mediating CTGF's growth factor action is unknown. ${ }^{46}$ Along with its action as a growth factor, CTGF has recently been implicated in fibroblasts as a bona fide adhesive substrate with activity mediated through $\alpha 6 \beta 1$ integrin. ${ }^{54}$ Importantly, CTGF is coordinately expressed with TGF- $\beta$ and demonstrates increased expression in numerous fibrotic disorders including systemic sclerosis, ${ }^{55,56}$ lung fibrosis, ${ }^{57}$ renal fibrosis, ${ }^{58,59}$ myocardial fibrosis, ${ }^{60}$ and atherosclerosis. ${ }^{61}$

CTGF has not been previously reported in the retina, vitreous, or vitreoretinal disease tissue, although it has been shown that vascular endothelial growth factor induces expression of CTGF in retinal vascular cells. ${ }^{62}$ We show here that there is strong immunoreactivity for CTGF in human PVR membranes. Much of the CTGF appears to be extracellular suggesting that the secreted protein may be bound to the extracellular matrix. We predict that since many of the CTGFpositive cells are also positive for cytokeratin (results not shown), that RPE will be found to produce CTGF. We also predict that CTGF will be found to be a major mediator of fibrosis in PVR. In the human PVR membranes that we examined, CTGF expression was prominent in both cellular and fibrotic areas of the membranes.

\section{Model for pathogenesis of PVR: the PVR cycle}

We propose a new model for the pathogenesis of PVR, based on the potential roles played by HGF and CTGF (Figure 2). In this model, injury to the retina induces an inflammatory response leading to the activation of RPE and upregulation of HGF expression. HGF induces the separation of RPE from the monolayer, inhibits apoptosis and promotes the formation of multilayered groups of dedifferentiated, migratory RPE. These RPE are present within a provisional extracellular matrix that includes thrombospondin (TSP). The RPE come into contact with vitreous that contains abundant inactive TGF- $\beta$. TGF- $\beta$ is activated by mechanisms including TSP, thus stimulating upregulation of CTGF in the RPE. Under the influence of TGF- $\beta$ and CTGF, the RPE become myofibroblastic and fibrosis ensues. The lesion becomes less cellular due to the pro-apoptotic effects of CTGF. The

\section{PVR Cycle}

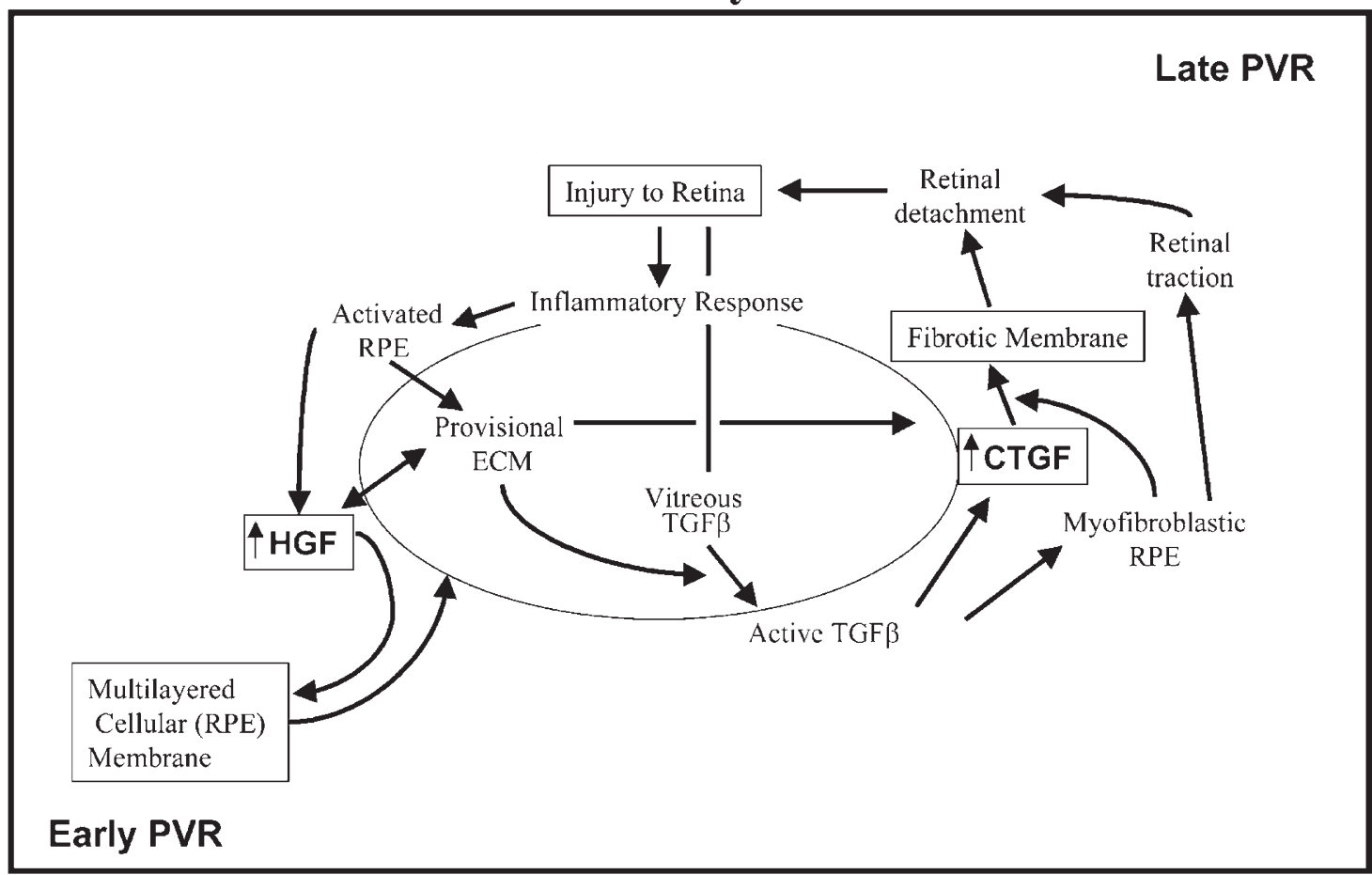

Figure 2 The PVR cycle. A model of pathogenesis of PVR is diagrammed showing the potential roles of the growth factors hepatocyte growth factor (HGF) and connective tissue growth factor (CTGF) in this process. 
myofibroblastic RPE contract and in conjunction with the fibrotic ECM induce traction on the retina. Retinal traction induces further retinal detachment, continuing the cycle of retinal injury.

\section{Acknowledgements}

The authors thank Fibrogen Inc (South San Francisco, CA, USA) for anti-CTGF antibody, and Eric Barron for assistance in the preparation of the figures. Supported by grants EYO2061 and EY03040 from the National Institutes of Health.

\section{References}

1 Ryan SJ. The pathophysiology of proliferative vitreoretinopathy and its management. Am J Ophthalmol 1985; 100: 188-193.

2 Cowley M, Conway BP, Campochiaro PA, Kaiser D, Gaskin H. Clinical risk factors for proliferative vitreoretinopathy. Arch Ophthalmol 1989; 107: 1147-1151.

3 Cardillo JA, Stout JT, LaBree L, Azen SP, Omphrey L, Cui JZ et al. Post-traumatic proliferative vitreoretinopathy. The epidemiologic profile, onset, risk factors, and visual outcome. Ophthalmology 1997; 104: 1166-1173.

4 Campochiaro PA. Pathogenesis of proliferative vitreoretinopathy. In: Ryan SJJ (ed). Retina, Vol 3. Mosby: St Louis, 3rd edn, 2001, pp 2221-2227.

5 Charteris DG. Proliferative vitreoretinopathy: pathobiology, surgical management, and adjunctive treatment. Br J Ophthalmol 1995; 79: 953-960.

6 Weller M, Esser P, Bresgen M, Heimann K, Wiedemann P. Thrombospondin: a new attachment protein in preretinal traction membranes. Eur J Ophthalmol 1992; 2: $10-14$.

7 Hiscott PS, Grierson I, McLeod D. Natural history of fibrocellular epiretinal membranes: a quantitative, autoradiographic, and immunohistochemical study. $\mathrm{Br} J$ Ophthalmol 1985; 11: 810-823.

8 Cordeiro MF, Schultz GS, Ali RR, Bhattacharya SS, Khaw PT. Molecular therapy in ocular wound healing. $\mathrm{Br} J$ Ophthalmol 1999; 83: 1219-1224.

9 Thumann G, Hinton DR. Cell biology of the retinal pigment epithelium. In: Ryan SJ (ed). Retina, Vol 3. Mosby: St Louis, 3rd edn, 2001, pp 104-121.

10 Anderson DH, Stern WH, Fisher SK, Erickson PA. The onset of pigment epithelium proliferation after retinal detachment. Invest Ophthalmol Vis Sci 1981; 21: 10-16.

11 Jin ML, He S, Worpel V, Ryan SJ, Hinton DR. Promotion of adhesion and migration of RPE cells to provisional extracellular matrices by TNF- $\alpha$. Invest Ophthalmol Vis Sci 2000; 41: 4324-2332.

12 Limb GA, Hollifield RD, Webster L, Charteris DG, Chignell AH. Soluble TNF receptors in vitreoretinal proliferative disease. Invest Opthalmol Vis Sci 2001; 42 1586-1591.

13 Campochiaro PA, Sugg R, Grotendorst G, Hjelmeland LM. Retinal pigment epithelial cells produce PDGF-like proteins and secrete them into their media. Exp Cell Res 1989; 49: 217-227.
14 Hinton DR, He S, Graf K, Yang D, Hsueh WA, Ryan SJ, Las RE. Mitogen activated protein kinase activation mediates PDGF-directed migration of RPE cells. Exp Cell Res 1998; 239: 11-15.

15 Andrews A, Balciunaite E, Leong FL, Tallquist M, Soriano P, Refojo M, Kazlauskas A. Platelet-derived growth factor plays a key role in proliferative vitreoretinopathy. Invest Ophthalmol Vis Sci 1999; 11: 2683-2689.

16 Ikuna Y, Leong F-L, Kazlauskas A. Attenuation of experimental proliferative vitreoretinopathy by inhibiting the platelet-derived growth factor receptor. Invest Ophthalmol Vis Sci 2000; 41: 3107-3116.

17 Seo MS, Okamato N, Vinores MA, Nivores SA, Hackett $\mathrm{SF}$, Yamada $\mathrm{H}$ et al. Photoreceptor-specific expression of platelet-derived growth factor-B results in traction retinal detachment. Amer J Pathol 2000; 157: 995-1005.

18 Pfeffer BA, Flanders KC, Guerin CJ, Danielpour D, Anderson DH. Transforming growth factor beta 2 is the predominant isoform in the neural retina, retinal pigment epithelium-choroid and vitreous of the monkey eye. Exp Eye Res 1994; 59: 323-333.

19 Connor Jr TB, Roberts AB, Sporn MB, Danielpour D, Dart LL, Michels RG et al. Correlation of fibrosis and transforming growth factor-beta type 2 levels in the eye. $J$ Clin Invest 1989; 83: 1661-1666.

20 Bornstein P. Thrombospondins as matricellular modulators of cell function. J Clin Invest 2001; 107: 929934.

21 Koli K, Saharinen J, Hyytianen M, Penttinen C, Keski-Oja J. Latency, activation, and binding proteins of TGF- $\beta$. Microsc Res Tech 2001; 52: 354-362.

22 Nakamura T, Teramoto H, Ishihara A. Purification and characterization of a growth factor from rat platelets for mature parenchymal hepatocytes in primary culture. Proc Natl Acad Sci USA 1986; 83: 6489-6493.

23 Naldini L, Weidner KM, Vigna E et al. Scatter factor and hepatocyte growth factor are indistinguishable ligands for the MET receptor. EMBO J 1991; 10: 2867-2878.

24 Grierson I, Heathcote L, Hiscott P, Hogg P, Briggs M, Hagan S. Hepatocyte growth factor/scatter factor in the eye. Prog Ret Eye Res 2000; 19: 779-802.

25 Zarnegar R, Michalopoulos GK. The many faces of hepatocyte growth factor: from hepatopoiesis to hematopoiesis. J Cell Biol 1995; 129: 1177-1180.

26 Weidner KM, Behrens J, Vandekerckhove J, Birchmeier W. Scatter factor: molecular characteristics and effect on the invasiveness of epithelial cells. J Cell Biol 1990; 111: 2097-2108.

27 He PM, He S, Garner JA, Ryan SJ, Hinton DR. Retinal pigment epithelial cells secrete and respond to hepatocyte growth factor. Biochem Biophys Res Commun 1998; 249: 253-257.

28 Lashkari K, Rahimi N, Kazlauskas A. Hepatocyte growth factor receptor in human RPE cells: implications in proliferative vitreoretinopathy. Invest Ophthalmol Vis Sci 1999; 40: 149-156.

29 Briggs MC, Grierson I, Hiscott P, Hunt JA. Active scatter factor (HGF/SF) in proliferative vitreoretinal disease. Invest Ophthalmol Vis Sci 2000; 41: 3085-3094.

30 Mitamura Y, Takeuchi S, Matsuda A, Tagawa Y, Mizue Y, Nushihira J. Hepatocyte growth factor levels in the vitreous of patients with proliferative vitreoretinopahty. Am J Ophthalmol 2000; 129: 678-680.

31 Lamszus K, Joseph A, Jin L, Yao Y, Chowdhury S, Fuchs 
A et al. Scatter factor binds to thrombospondin and other extracellular matrix components. Amer J Pathol 1996; 149: 805-819.

32 Pasdar M, Li Z, Marreli M, Nguyen BT, Park M, Wong $\mathrm{K}$. Inhibition of junction assembly in cultured epithelial cells by hepatocyte growth factor/scatter factor is concomitant with increased stability and altered phosphorylation of the soluble junctional molecules. Cell Growth Diff 1997; 8: 451-462.

33 Grisendi S, Arpin M, Crepaldi T. Effect of hepatocyte growth factor in assembly of zonula occludens-1 protein at the plasma membrane. J Cell Physiol 1998; 176: 465-471.

34 Hiscox S, Jiang WG. Hepatocyte growth factor/scatter factor disrupts epithelial tumour cell-cell adhesion: involvement of $\beta$-catenin. Anticancer Res 1999; 19: 509518

35 Jiang WG, Martin TA, Matsumoto K, Nakamura T, Mansel RE. Hepatocyte growth factor/scatter factor decreases the expression of occludin and transendothelial resistance (TER) and increases paracellular permeability in human vascular endothelial cells. J Cell Physiol 1999; 181: 319-329.

36 Yamamoto K, Morishita R, Hayashi S, Matsushita H, Nakagami H, Moriguchi A et al. Contribution of Bcl-2 but not Bcl-xL and Bax to antiapoptotic actions of hepatocyte growth factor in hypoxia-conditioned human endothelial cells. Hypertension 2001; 37: 1341-1348.

37 Wang H, Keiser JA. Hepatocyte growth factor enhances MMP activity in human endothelial cells. Biochem Biophys Res Commun 2000; 272: 900-905.

38 Taniyama Y, Morishita R, Nakagami H, Moriguchi A, Sakonjo H, Shokei K et al. Potential contributions of a novel antifibrotic factor, hepatocyte growth factor, to prevention of myocardial fibrosis by angiotensin II blockade in cardiomyopathic hamsters. Circulation 2000; 102: $246-252$.

39 Mizuno S, Matsumoto K, Nakamura T. Hepatocyte growth factor suppresses interstitial fibrosis in a mouse model of obstructive nephropathy. Kidney Int 2001; 59: 1304-1314.

40 Dohi M, Masegawa T, Yamamoto K, Marshall BC. Hepatocyte growth factor attenuates collagen accumulation in a murine model of pulmonary fibrosis. Am J Respir Crit Care Med 2000; 162: 2302-2307.

41 Gohda E, Takebe T, Sotani T, Nakamura S, Minowada J, Yamamoto I. Induction of hepatocyte growth factor/scatter factor by interferon-gamma in human leukemia cells. J Cell Physiol 1998; 174: 107-114.

42 Manganini M, Maier JAM. Transforming growth factor $\beta 2$ inhibition of hepatocyte growth factor-induced endothelial proliferation and migration. Oncogene 2000; 19: $124-133$

43 Jin ML, Barron E, He S, Ryan SJ, Hinton DR. Regulation of RPE intercellular junction integrity and function by hepatocyte growth factor. Invest Ophthalmol Vis Sci 2002 (in press).

44 Jin ML, Chen Y, He S, Spee C, Ryan SJ, Hinton DR. Overstatement of hepatocyte growth factor (HGF) in the retinal pigment epithelium induces development of subretinal membranes and chronic retinal detachment (Abstract). Invest Ophthalmol Vis Sci 2002; 43.

45 Grodendorst GR. Connective tissue growth factor: a mediator of TGF- $\beta$ action on fibroblasts. Cytokine Growth Factor Rev 1997; 8: 171-179.
46 Perbal B. NOV (nephroblastoma overexpressed) and the $\mathrm{CCN}$ family of genes: structural and functional issues. $J$ Clin Pathol: Mol Pathol 2001; 54: 57-74.

47 Ryseck R-F, Macdonald-Bravo H, Mattei M-G, Bravo R. Structure, mapping, and expression of fisp-12, a growth factor-inducible gene encoding a secreted cysteine-rich protein. Cell Growth Diff 1991; 2: 225-233.

48 Steffen CL, Ball-Mirth DK, Harding PA, Bhattacharyya N Pillai S, Brigstock DR. Characterization of cell-associated and soluble forms of connective tissue growth factor (CTGF) produced by fibroblast cells in vitro. Growth Factors 1998; 15: 199-213.

49 Yang DH, Kim HS, Wilson EM, Rosenfeld RG, Oh Y. Identification of glycolyslated $38-\mathrm{kDa}$ connective tissue growth factor (IGFBP-related protein 2) and proteolytic fragments in human biological fluids, and up-regulation of IGFBP-rP2 expression by TGF- $\beta$ in Hs578T human breast cancer cells. J Clin Endocrinol Metabol 1998; 83: 2593-2596.

50 Ball DK, Surveyor GA, Diehl JR, Steffen CL, Uzumcu M, Mirando MA, Brigstock DR. Characterization of 16- 20kilodalton ( $\mathrm{kDa}$ ) connective tissue growth factors (CTGFs) and demonstration of proteolytic activity for $38-\mathrm{kDa}$ CTGF in pig uterine luminal washings. Biol Reproduct 1998; 59: 828-835.

51 Frazier K, Williams S, Kothapalli D, Klapper H, Grotendorst GR. Stimulation of fibroblast cell growth, matrix production, and granulation tissue formation by connective tissue growth factor. J Invest Dermatol 1996; 107: 404-411.

52 Hishikawa K, Oemar BS, Tanner FC, Nakaki T, Fujii T, Luscher TF. Overexpression of connective tissue growth factor gene induces apoptosis in human aortic smooth muscle cells. Circulation 1999; 100: 2108-2112.

53 Hishikawa K, Nakaki T, Fujii T. Connective tissue growth factor induces apoptosis via caspase 3 in cultured human aortic smooth muscle cells. Eur J Pharmacol 2000; 392: 1922.

54 Chen CC, Chen N, Lau LF. The angiogneic factors cyr61 and connective tissue growth factor induce adhesive signaling in primary human skin fibroblasts. J Biol Chem 2001; 276: 10443-10452.

55 Sato S, Nagoaka T, Hasegawa M, Tamatani T, Nakanishi $\mathrm{T}$, Takigawa M, Takehara K. Serum levels of connective tissue growth factor are elevated in patients with systemic sclerosis: association with extent of skin sclerosis and severity of pulmonary fibrosis. J Rheumatol 2000; 27: 149-154.

56 Shi-Wen X, Pennington D, Holmes A, Leask A, Bradham $\mathrm{D}$, Beauchamp JR et al. Autocrine overexpression of CTGF maintains fibrosis: RDA analysis of fibrosis genes in systemic sclerosis. Exp Cell Res 2000; 25: 213-224.

57 Lasky JA, Ortiz LA, Tonthat B, Hoyle GW, Corti M, Athas $\mathrm{G}$ et al. Connective tissue growth factor mRNA expression is upregulated in bleomycin-induced lung fibrosis. Am J Physiol 1998; 275: L365-371.

58 Ito Y, Aten J, Bende RJ, Oemar BS, Rabelink TJ, Weening JJ, Goldschmeding R. Expression of connective tissue growth factor in human renal fibrosis. Kidney Internat 1998; 53: 853-861.

59 Clarkson MR, Gupta S, Murphy M, Martin F, Godson C, Brady HR. Connective tissue growth factor: a potential stimulus for glomeruloslcerosis and tubulointerstitial 
fibrosis in progressive renal disease. Curr Opin Nephrol Hypertens 1999; 8: 543-548.

60 Chen MM, Lam A, Abraham JA, Schreiner GF, Joly AH. CTGF expression is induced by TGF-beta in cardiac fibroblasts and cardiac myocytes: a potential role in heart fibrosis. J Mol Cell Cardiol 2000; 32: 1805-1819.

61 Oemar BS, Werner A, Garnier J-M, Do D-D, Godoy N, Nauck $\mathrm{M}$ et al. Human connective tissue growth factor is expressed in advanced atherosclerotic lesions. Circulation 1997; 95: 831-839.

62 Suzuma K, Naruse K, Suzuma I, Takahara N, Ueki K, Aiello LP, King GL. Vascular endothelial growth factor induces expression of connective tissue growth factor via KDR, Flt1 and phosphatidylinositol 3-kinase-aktdependent pathways in retinal vascular cells. J Biol Chem 2000; 52: 40725-40731. 